\title{
Representações de gênero na literatura evangélica
}

\author{
Sandra Duarte de Soura*
}

\section{Resumo}

A literatura evangélica direcionada ao público feminino, não raras vezes se apresenta como um "manual de conduta" para as mulheres, visando "aconselhá-las" em seu cotidiano. Este artigo exibe e analisa as representações de gênero evocadas nesse tipo de literatura, com especial enfoque para cinco títulos que durante anos estiveram entre os mais vendidos no Brasil e que têm as mulheres como público-alvo. Verifica-se que as representações de gênero dominantes nesse tipo de literatura afirmam uma mulher paradigmática, cuja identidade constitui-se necessária e obrigatoriamente por meio do casamento e da maternidade.

Palavras-chave: Representações de gênero. Mulheres. Literatura evangélica.

\section{Gender representations on gospel literature}

\begin{abstract}
The Gospel literature directed at the female audience, often presents itself as a "guide of conduct" for women, aiming to "advise" them in their daily life. This article introduces and analyzes gender representations mentioned in this kind of literature, with special focus to five titles that for years were among the most sold in Brazil and they have women as target audience. It turns out that the dominant gender representations in this kind of literature, claim a paradigmatic woman whose identity is necessarily and obligatorily built through marriage and motherhood.
\end{abstract}

Key-words: Gender representations. Women. Gospel literature.

* Doutora em Ciências da Religião, professora do Programa de Pós-Graduação em Ciências da Religião da Universidade Metodista de São Paulo - UMESP e coordenadora do Grupo de Estudos de Gênero e Religião - MANDRÁGORA/NETMAL. E-mail: sanduarte3@ gmail.com 


\section{Representaciones de género en la literatura evangélica}

\section{Resumen}

La literatura evangélica dirigida al público femenino, a menudo se presenta como un "manual de conducta" para las mujeres, con el objetivo de les "asesorar" en su vida diaria. Este artículo presenta y analiza las representaciones de género mencionadas en este tipo de literatura, con especial atención a cinco títulos que por años estuvieran entre los más vendidos en Brasil y que tienen las mujeres como público objetivo. Resulta que las representaciones de género dominantes en este tipo de literatura reclaman una mujer paradigmática, cuya identidad es necesaria y obligatoriamente a través del matrimonio y de la maternidad.

Palabras clave: Representaciones de género. Mujeres. Literatura evangélica.

\section{Introdução}

Durante longos anos da história do Ocidente, as mulheres foram privadas do direito de aprender a ler e escrever. O desejo feminino de saber foi sistematicamente reprimido. A desobediência à norma, não raras vezes, lhes custou punições físicas, internações sob o diagnóstico de loucura e também a morte. O estranhamento ocidental de casos como o de Malala, ${ }^{1}$ a jovem paquistanesa que sofreu um atentado do Talibã, em 2012, por defender a educação de meninas, não foi muito além de uma indignação com o inventado "Oriente" (SAID, 1990) em sua brutalidade sexista, relegando ao esquecimento a também misógina sociedade ocidental contemporânea.

A orientação patriarcal de que o objetivo último da existência das mulheres é o casamento e a maternidade estabelecia e ainda estabelece limites claros quanto àquilo que deve ser objeto de sua dedicação: o marido, a prole e a casa. Tais tarefas prescindiriam do aprendizado da leitura e da escrita. As letras estariam destinadas aos homens, cuja identidade se teceria pela participação na vida pública. Além do mais, o silenciamento das mulheres seria uma das mais importantes formas de dominação das mesmas. Como afirma Michelle Perrot, as mulheres deveriam "aceitar, conformar-se, obedecer, submeter-se e calar-se. Este mesmo silêncio, imposto pela ordem simbólica, não é somente o silêncio da fala, mas também o da expressão, gestual ou escriturária" (2008, p. 10).

Certamente, a situação das mulheres ocidentais no século XXI quanto ao acesso aos estudos é bem distinta da situação dos séculos anteriores.

\footnotetext{
1 Para conhecer a história de Malala, veja sua biografia em Meu nome é Malala (YOUSAFZAI, 2013).
} 
Atualmente, não há país ocidental que proíba, em termos legais, o acesso de mulheres à educação formal não significando, porém, que não haja obstáculos de gênero, raça/etnia e classe que dificultam tal acesso. Um exemplo de tais obstáculos tem a ver com o fato de, em muitos países, inclusive no Brasil, as mulheres terem carga horária de trabalho superior à dos homens, uma vez que ainda hoje persiste uma distribuição desigual quanto às atribuições das tarefas domésticas. Isso se agrava ainda mais no caso de mulheres pobres, considerando-se o alto número de meninas que experimentam o peso do trabalho doméstico desde a mais tenra idade. A Síntese de Indicadores Sociais (2016) revelou que em 2015, em atividades remuneradas, as mulheres brasileiras trabalharam seis horas semanais a menos que os homens, porém, trabalharam duas vezes mais em tarefas domésticas. No cômputo geral, as mulheres tiveram uma jornada de cerca de cinco horas semanais a mais do que os homens, desenvolvendo atividades remuneradas e atividades domésticas em geral. Enquanto a jornada semanal masculina chegou a 50,5 horas, a das mulheres foi de 55,1 horas. Isso indica que as mulheres empenham mais de 20 horas mensais do que os homens no trabalho. Isso tem impacto também no tempo disponível para estudos e lazer.

Mesmo diante desse dado, a pesquisa Retratos da Leitura no Brasil, do Instituto Pró-Livro, indica que em nosso país as mulheres leem mais do que os homens. Desde o primeiro levantamento realizado pelo Instituto, no ano 2000, e publicado em 2001, as mulheres sempre estiveram à frente dos homens no volume anual de leitura. Na primeira edição da pesquisa (2001), as mulheres contabilizavam $51 \%$ da população leitora; na segunda edição (2008), as mulheres chegaram a 55\%; em 2011, por ocasião de sua terceira edição, a porcentagem de leitoras foi de $53 \%$; e em sua $4^{\text {a }}$. edição, o Instituto Pró-Livro identificou que $59 \%$ da população feminina leu um livro ou parte de um livro nos três meses anteriores à pesquisa.

O tipo de literatura, porém, indica uma preferência feminina por romances e livros religiosos, enquanto entre os homens, predominam leituras sobre política e economia. A Bíblia é o livro mais lido em todas as edições da pesquisa por ambos os sexos, sendo mais lida pelas mulheres do que pelos homens. $\mathrm{O}$ mesmo em se tratando de livros religiosos. A pesquisa também demonstrou que quanto maior a escolaridade e o nível de renda, menor o interesse por livros de caráter religioso e tanto maior o interesse por livros científicos, havendo maior penetração da Bíblia nos estratos de baixa escolaridade e baixa renda, especialmente mulheres. 
O perfil da leitora brasileira, especialmente sua preferência por literatura religiosa, justifica nosso olhar sobre o que está se produzindo para esse público leitor. Se é verdade que as mulheres leem mais e que leem especialmente livros religiosos, que representações de gênero são comunicadas por esse tipo de literatura?

Para respondermos a essa pergunta, separamos alguns dos livros evangélicos mais conhecidos direcionados ao público feminino, evangélico ou não. Nosso objetivo foi levantar e analisar as representações de gênero mais frequentes nesse tipo de literatura religiosa. Os textos analisados foram os seguintes: O poder da esposa que ora, de Stormie Omartian (1998); A Mulher controlada pelo Espírito, de Beverly LaHaye (1981); A esposa que quero ser, de Judith Kemp (2006); Megatendências para a Mulher Cristã, de Rozane Rangel da Cunha (1995); e A dama, seu amado e seu Senhor, de Thomas D. Jakes (1999).

\section{As mulheres no foco da produção religiosa escrita}

As últimas décadas têm testemunhado um alto investimento editorial na produção de CDs, DVDs e livros evangélicos cujo público-alvo extrapola as pessoas autodeclaradas evangélicas. O mercado consumidor desses produtos está em alta em várias partes do mundo. Em relação aos livros, novos títulos são publicados em ritmo acelerado, e têm figurado entre os mais vendidos. Tome-se como exemplo os livros do pastor estadunidense Max Lucado, que já vendeu mais de 70 milhões de exemplares dos seus mais de setenta livros. Na Amazon.com, segundo levantamento do site GLivros do Gospel Mais, dos dez livros evangélicos mais vendidos no Brasil nos últimos tempos, sete são de Lucado. ${ }^{2}$

Desde as prateleiras das livrarias, sejam elas evangélicas ou seculares, passando por sites de divulgação e venda de livros em geral e outras mídias, a literatura evangélica já não está mais restrita à ação de colportores religiosos para a sua propagação. Os meios de comunicação do ideário evangélico são múltiplos, mas é claro que a boa propaganda do "boca a boca" e as reuniões semanais ou quinzenais de grupos societários (jovens, mulheres, homens etc.) para discutir uma publicação evangélica também ajudam no processo de divulgação e de cristalização da ideologia veiculada nesses textos. Além disso, o recurso de divulgação de livros em catálogos de cosméticos para mulheres já está sendo utilizado pelas editoras, alcançando importante fatia consumidora.

\footnotetext{
2 Os 10 livros cristãos/evangélicos mais vendidos na Amazon.com.br Disponível em: https:// livros.gospelmais.com.br/cristaos-evangelicos-mais-vendidos-amazon-com-br Acesso em: 5 de jul. 2017.
} 
Os livros evangélicos têm sido apresentados como verdadeiros manuais de autoajuda ${ }^{3}$ e explicitam como objetivo ajudar a mulher contemporânea a administrar sua vida, em especial sua vida conjugal, sendo seu conteúdo perpassado pelas representações de gênero dominantes em nossa sociedade. Mas, qual seria o público-alvo desse tipo de publicação? Quais seriam os sujeitos preferenciais para a recepção e reprodução desse discurso? A quem, em última instância, se destina a regulação religiosa contida nessa literatura?

Eliane Moura da Silva, ao escrever sobre as questões de gênero que perpassam o que ela denomina de fundamentalismo evangélico, afirma que este

Investe na família como um lugar privilegiado para a educação e a transmissão dos valores religiosos de uma geração para a outra. Como um microcosmo de uma ordem moral universal, as relações inter-pessoais entre pais e filhos, marido e mulher são usadas como exemplos das relações ideais entre a humanidade e a divindade. A família tornou-se um núcleo tão fundamental deste pensamento religioso que quaisquer mudanças sociais, econômicas, políticas ou culturais causadoras de transformações nestes determinados padrões de família são vistos como profundamente ameaçadores dos fundamentos religiosos (2006, p. 18).

Os textos evangélicos que compõem nosso corpus de análise comungam dessa ideia. A família constitui-se como lócus fundamental de produção e transmissão de valores religioso-culturais, e esses valores são generificados. Os textos evocam o caráter divino das representações de gênero, reservando para as mulheres o segundo lugar na hierarquia dos sexos.

Nos Estados Unidos, a literatura evangélica atinge os mais diversos segmentos, mas o público preferencial é o feminino que, diga-se de passagem, em geral lê mais do que o masculino. O conteúdo desses textos tende a ser de cunho conservador, reforçando aspectos relacionados à moral sexual e aos papéis sociais dos sexos historicamente afirmados por uma cosmovisão fundamentada na desigualdade de gênero. No Brasil, a situação é exatamente a mesma. Os livros evangélicos mais vendidos aqui são praticamente os mesmos mais vendidos nos EUA. O mercado editorial brasileiro descobriu no segmento de livros religiosos um importante nicho a ser explorado. Esse é o segmento que mais tem crescido nos últimos anos, e coloca em pauta a necessária discussão da literatura religiosa como uma importante expressão da

3 A partir desse ponto apresentamos parte do capítulo de nossa autoria intitulado "O gênero escrito na literatura evangélica" (SOUZA, 2011) 
produção e consumo de bens simbólicos religiosos no meio evangélico. Com linguagem acessível, em estilo de literatura de autoajuda, os livros evangélicos ocupam as prateleiras de livrarias religiosas e seculares, sendo alocados de maneira variada entre as seções de livros religiosos e de autoajuda.

Conforme indicamos no início deste artigo, a pesquisa "Retratos da Leitura no Brasil" (INSTITUTO PRÓ-LIVRO), publicada em 2001, 2008, 2012 e 2016, já apontava que a literatura mais lida em nosso país é a religiosa e que, de longe, o público feminino é o seu maior consumidor.

Apesar de uma relativa autonomia da produção literária evangélica em relação às instituições religiosas, visto cederem às pressões do mercado e, portanto, sugerirem certo afrouxamento dos aspectos doutrinais institucionais, verifica-se que esse tipo de literatura não rompe com as representações de gênero dominantes no campo religioso. A mulher é representada como submissa, sofredora, responsável pela casa e pelo equilíbrio familiar, e sua identidade se constrói em função do marido. Em parte isso pode ser explicado pela sintonia entre o sistema simbólico religioso e os demais sistemas de sentido que predominam em nossa sociedade.

Conforme afirma Roger Chartier, nem as inteligências nem as ideias são desencarnadas (1991, p. 180). Os discursos religiosos, como quaisquer discursos, derivam de interesses culturais. Eles se tecem no emaranhado de sentido chamado cultura que, segundo Clifford Geertz, pode ser traduzida como: um sistema de concepcões herdadas expressas em formas simbólicas por meio das quais os homens [e mulheres] comunicam, perpetuam e desenvolvem seu conbecimento e suas atividades em relação à vida (1989, p. 102). A constituição e a perpetuação de padrões culturais estão associadas à sua capacidade de transmissão, daí Geertz ressaltar a variedade de mecanismos responsáveis por essa transmissão e perpetuação, entre os quais a arte, a ciência, o comércio, a política, as formas de lazer, a vida cotidiana e a religião (1998, p. 145).

É no campo da religião que queremos nos situar, porém, esse campo não existe completamente autônomo dos demais, ele é parte dessa teia de sentidos que chamamos cultura. A recepção "acomodada" de um discurso religioso só pode acontecer dessa forma, porque esse discurso não destoa daquilo que está objetivado socialmente e que compõe o sistema de sentido em que se está inserido. Essa herança cultural, por força dos mecanismos de dominação social, tende a ser reproduzida como dado natural e, no caso da religião, como dado sobrenatural. Em se tratando das relações de gênero, a religião é um dos mecanismos mais eficazes de legitimação e reprodução da assimetria entre os sexos (BOUVAY, 1996, p. 143-161). Essa eficácia está diretamente relacionada à capacidade da religião de relacionar com a realidade suprema as precárias construções da realidade erguidas pelas sociedades empiricas (BERGER, 1985, p. 45), isto é, à sua 
capacidade de sacralizar determinados códigos culturais. Daí não nos causar estranheza o apelo, contido nos textos selecionados, à sacralidade das relações de dominação de gênero que se tecem no interior (e no exterior) da casa: Deus tem dado aos nossos maridos o privilégio de serem os lideres espirituais do lar (...) Portanto, uma mulher submissa é aquela que está ajudando seu marido a ser um sucesso no seu papel de sacerdote do lar (KEMP, 2006, p. 19).

\section{O gênero do discurso evangélico}

Para entender o complexo da produção de um discurso, é preciso entendê-lo dentro de um conjunto de códigos culturais que estabelecem uma identificação entre emissor e receptor. A mulher representada na literatura evangélica é de classe média alta, casada, com bom nível de instrução, com vida profissional autônoma, com marido bem-sucedido profissionalmente, com poucos filhos e com casa própria. Para além da identidade de classe, isso força também uma identificação étnico-racial, haja vista que, por força das desigualdades sociais construídas sobre as diferenças étnico-raciais, as mulheres que se encontram nessas condições em nossa sociedade são majoritariamente brancas. Esse é o ideal de mulher e de família propagado culturalmente e assimilado de tal forma que as leitoras, mesmo em condições distintas desse ideal de mulher e família, sentem-se identificadas com essa mensagem e estimuladas a perseguir esse ideal. As capas dos livros em questão são muito elucidativas a esse respeito. Há uma variação das capas conforme a edição do livro, mas há uma sintonia na representação do feminino como a imagem esfumaçada ou desfocada de uma mulher branca (CUNHA, 1995; LAHAYE, 1981; OMARTIAN, 1998).
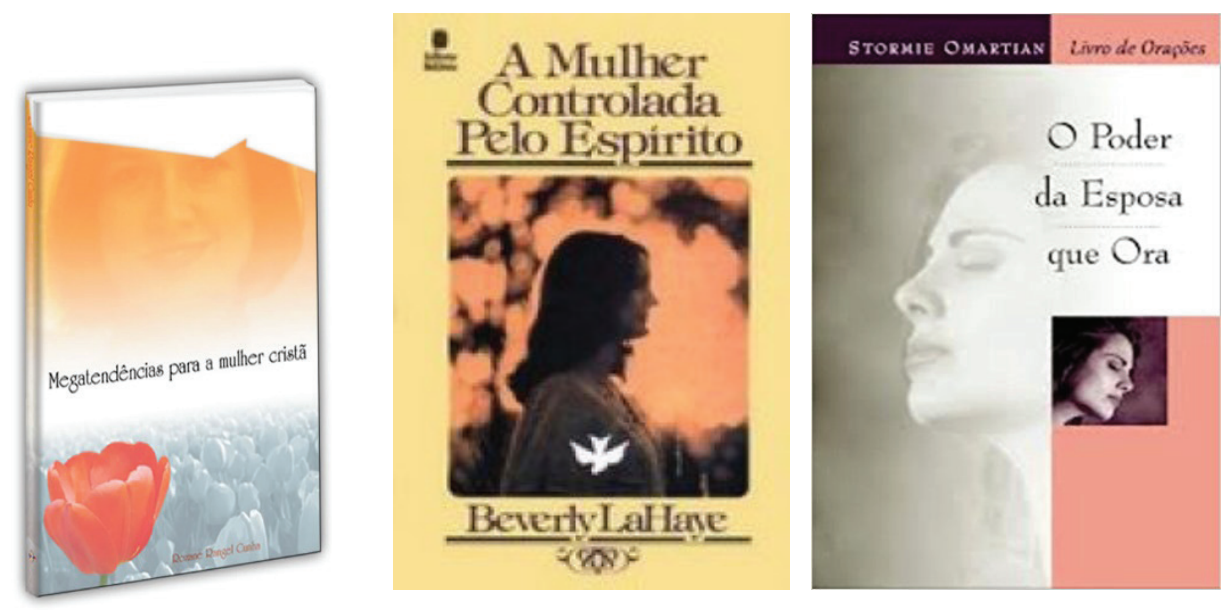
É importante ressaltar tanto o aspecto étnico-racial comunicado por essa imagem, quanto o aspecto de anulação do feminino, apresentado na figura esfumaçada ou desfocada. Essa primeira identificação é fundamental, pois ela alicerça a forma de recepção das demais representações contidas no discurso.

Os textos que compõem nosso corpus de análise são discursos elaborados para tratar das mudanças sociais, em especial mudanças que afetaram o universo feminino. Busca-se adaptar o discurso religioso às transformações experimentadas na sociedade contemporânea. A chamada mulher moderna é o alvo dessa literatura, que visa, em última instância, adequar a crescente autonomização das mulheres à necessidade existencial patriarcal da regulação religiosa do feminino. A mulher ideal, isto é, a mulher paradigmática que é apresentada em cada texto, é uma mulher travestida de modernidade que representa a continuidade das representações seculares de um feminino constituído pelo e para o outro. Ela soma todas as vantagens de ser bem-sucedida no mundo público, possuindo relativa autonomia financeira e emocional, com as atribuições de ser a cuidadora da casa, dos filhos e, especialmente, do marido. Deve-se lembrar, entretanto, que sua missão primordial é o cuidado familiar, sendo a inserção no mundo público um apêndice de sua identidade, pois o homem não deve casar-se com a mulher que considera sua carreira uma missão (JAKES, p. 134). A ênfase no cuidado com o lar, na aceitação resignada das tarefas domésticas é traduzida na Oração da Cozinha, de autoria desconhecida, e que Beverly LaHaye fez questão de reproduzir em seu livro (1981, p. 49):

Ó Senhor de todas as panelas e outros utensílios

Como eu não tenho tempo para ser

Um santo a realizar belas ações

Ou a vigiar, nas horas tardias da noite,

Ou sonhar à luz das madrugadas

Ou bater aos portões dos céus,

Torna-me uma santa que prepara refeições,

E lava as louças.

Aquece esta cozinha com teu amor

Ilumina-a com a tua par.

Perdoa-me por todas as minhas preocupações

E faz cessar minhas murmurações.

Tu que te deleitavas em dar alimento aos homens

Em casa ou à beira-mar.

Aceita o serviço que presto

Pois o faço para te adorar 
Outra representação que predomina nos textos analisados e que está completamente atrelada a essa, é que as mulheres são construídas como o "outro" dos homens, que são apresentados como sujeitos paradigmáticos:

Quando Ad̃a está ausente, a dama sente-se perdida. Ele é a música para a qual ela foi criada, ela é a harmonia que cerca a sua melodia (JAKES, p. 78).

Ela foi criada especialmente para ele, para satisfazer todas as suas necessidades e desejos (JAKES, p. 75)

As mulheres são apresentadas como as mulheres dos homens, e suas virtudes se consolidam na sujeição a eles e na neutralização de seu próprio eu. Em "A Mulher controlada pelo Espírito", Lahaye dedica-se à afirmação da renúncia feminina. Segundo ela, as mulheres deveriam deixar-se controlar pelo Espírito, que as conduziria da forma que lhe aprouvesse: precisamos nos dispor a largar mão de nós mesmas e sermos controladas por Deus, e fazer de nossa vida aquilo que o Espirito Santo desejar (1981, p. 16). Essa submissão à vontade do Espírito significaria também a submissão à vontade do marido e o abandono à crítica contra as suas atitudes. A autora menciona o caso de uma mulher que buscou aconselhamento porque estava com problemas conjugais:

O marido não era o homem que ela pensara, antes de casar-se. Não era trabalhador e produtivo, nem tinha espirito de luta, e era muito desorganizado; não a ajudava nas tarefas da casa, nem era forte sexualmente. Ela sentia que a vida lhe fora bastante injusta. Atravessava crises de depressão e já havia até pensado em dar cabo da própria vida. Após ouvi-la desfiar seu rosário de problemas, mostrei-lhe que todas as suas declarações eram apenas críticas contra o marido (...) Minha última tentativa seria mandá-la voltar para casa, e, durante uma semana, procurar fazer uma lista dos traços positivos que pudesse encontrar no caráter dele. Eu disse a ela que se tivesse muita dificuldade em encontrar elementos para formular a lista, que pedisse o auxílio divino. Na semana seguinte ela voltou e disse que nos três primeiros dias não encontrava nada para anotar. Por fim, pediu a Deus que a ajudasse a enxergar se havia alguma coisa de valor naquele homem. Então, fer. uma lista que constava de quatro itens: 1) ele era bondoso para com os filhos; 2) era generoso com seu dinheiro; 3) era respeitado na igreja por ser bom instrutor bíblico; 4) era fiel a ela. Seu espirito de crítica para com o marido estava arruinando seu casamento e sua vida. Ela confesson este pecado e pediu a Deus que a ajudasse a deixar de ser tão crítica (1981, p. 17-18).

Lahaye responsabiliza a mulher pelos problemas conjugais que esta está vivendo. Ela vive com um homem que não gosta de trabalhar, é desorganizado, a deixa sobrecarregada com as tarefas domésticas e não a satisfaz 
sexualmente. A reação da mulher é de inconformismo com a atitude do marido. Ela se percebe sobrecarregada, explorada e enganada, pois acreditava, até antes do casamento, que ele era diferente daquilo que se mostrou depois. A estratégia de Lahaye é minimizar o problema e transferir a responsabilidade do mesmo para a mulher. Afinal, é o seu espírito de crítica que está arruinando seu casamento e sua vida. Esse recurso da culpabilização das mulheres é frequente no campo religioso. Um aconselhamento pastoral, que poderia contribuir com o processo de autonomia dessa mulher, a encarcera ainda mais nas representações de um feminino acrítico, dependente e culpado.

Tomas Dexter Jakes, em A Dama, seu Amado e seu Senhor, segue na mesma linha, afirmando que a mulher que se rebela contra determinadas situações nada mais é do que um animal doméstico brincando de selvagem (1999, p. 50). Ele desqualifica a verbalização dos problemas pelas mulheres como sendo invencionices mentais e demônios que precisam ser exorcizados (1999, p. 45), pura implicação também conforme Stormie Omartian (1998, p. 28). O recurso à desqualificação tem sido historicamente utilizado como estratégia de desarticulação de movimentos de resistência à ordem estabelecida, e isso se verifica também quando analisamos a literatura evangélica em perspectiva de gênero. A explicitação dos problemas domésticos/conjugais experimentados pelas mulheres explicita também a precariedade da ordem sobre a qual se assentam as divisões sexuais. Isso descortinaria a artificialidade das relações de gênero. As representações dominantes do feminino e do masculino são apresentadas como dado natural e divino, portanto, são consideradas imutáveis. $\mathrm{Na}$ medida em que essas representações são questionadas, elas ameaçam a plausibilidade do sistema sexo/gênero.

Nos textos analisados, existe unanimidade na isenção do homem de responsabilidade sobre os problemas do casamento. Se ele não está correspondendo às expectativas sociais daquilo que é ser um bom marido, a mulher deve ser compreensiva e não confrontá-lo com essa situação:

Deus colocon o marido como cabeça da família, quer ele mereça ou não, quer ele desempenhe essa função adequadamente ou não. Essa é a ordem de Deus para as coisas (...) Se o seu marido deve ser o cabeça da casa, você tem de permitir-lhe a liderança (...) ainda que você contribua de modo relevante para o sustento financeiro. Tentar inverter essa ordem dá lugar a um constante conflito (OMARTIAN, p. 34).

Portanto, qualquer contestação dessa divisão sexual dos papéis sociais é considerada contestação da ordem divina. O apelo à tradição bíblica é um 
recurso bastante recorrente. A palavra autorizada legitima os usos e abusos de gênero, sacralizando a desigualdade entre os sexos: a Bíblia adverte, entretanto, que a mulher deve submeter-se a um homem pelo casamento, não por causa do sexo, mas por causa da sua posição que lhe dá cobertura e proteção (JAKES, 1999, p. 73).

O nomos social ganha status de nomos sagrado, transformando-se numa metarrealidade intocável pela crítica humana, legitimando assim a dominação, e contribuindo para a sua perpetuação. A religião contribui assim para aquilo que Bourdieu chamou de eternização das estruturas da divisão sexual (1999, p. 5). Essa divisão sexual está tão objetivada socialmente que se apresenta como legítima por si mesma:

A força da ordem masculina pode ser aferida pelo fato de que ela não precisa de justificação: a visão androcêntrica se impõe como neutra e não tem necessidade de se enunciar, visando sua legitimação (1999, p. 15).

Ao questionar a conduta do marido, a mulher estaria questionando a ordem, provocando a anomia, o que significaria a desestabilização do nomos. Daí o recurso constante a mecanismos de legitimação da dominação de gênero, nesse caso o recurso ao discurso religioso que é evocado não apenas para indicar o caráter divino da soberania masculina, mas também para afirmar o caráter divino da submissão feminina: Na bierarquia de Deus temos que ser submissas ao Senhor; em segundo lugar, ao marido. Quer a mulher queira quer não, ordena a Palavra de Deus que ela seja submissa (CUNHA, 1995, p. 43).

A afirmação da submissão feminina, a domesticação dos corpos e mentes das mulheres, seu disciplinamento (FOUCAULT, 2007), responde aos propósitos de uma sociedade patriarcal. Esse é o pressuposto da dominação de gênero, que se constrói arbitrariamente sobre as diferenças biológicas, produzindo assimetrias entre os sexos ancoradas em representações culturais de um masculino poderoso e digno de obediência e de um feminino frágil e naturalmente submisso. É no corpo das mulheres que se inscreve o texto da dominação. Ele é

Uma poderosa forma simbólica, uma superficie na qual as formas centrais, as bierarquias e até os comprometimentos metafísicos de uma cultura são inscritos e assim reforçados através da linguagem corporal concreta (BORDO, 1997, p. 19).

Com uma linguagem que evoca o belo, o suave, o delicado, o jardim onde a fome é saciada, Jakes (1999) nos apresenta um feminino domesticado, 
sujeito à vontade de poder do masculino. À primeira vista o autor, sempre elogioso em relação às mulheres contemporâneas, reconhece os seus atributos, e destaca que elas estão cada vez mais presentes na vida pública, entrando em espaços que, tempos atrás, eram herméticos à sua participação. Porém, uma leitura mais atenta explicitará o verdadeiro objetivo do texto, que é o de devolver a normalidade das relações sociais entre os sexos. Em suas palavras: nosso desejo no momento é a volta dos antigos valores (JAKES, 1999, p. 67).

O foco dessa literatura está voltado para o casamento, admitido como destino último das mulheres (JAKES, 1999, p. 83; OMARTIAN, p. 9-11). O casamento é concebido como instituição sagrada, cujo organograma não deixa dúvidas acerca de quem é o chefe principal: o marido. Este é desenhado como o salvador das mulheres e, mesmo em situações conflitantes, é melhor estar com ele do que sem ele, pois no caso de uma separação as perguntas que emergiriam naturalmente seriam: onde iria morar, como me sustentaria e cuidaria dos filhos, quem continuaria a ser meu amigo e, pior de tudo, como o divórcio afetaria men filho e minha filha (OMARTIAN, 1998, p. 11).

Paradoxalmente, atribui-se às mulheres a responsabilidade pelo equilíbrio do lar. Porém, é importante destacar que isso que é apresentado como uma forma de poder feminino nada mais é que um mecanismo de dominação de gênero. Para garantir o equilíbrio do lar, as mulheres devem silenciar, evitando murmurações e lamúrias (CUNHA, 1995, p. 35), pois é insensato manifestar todo tipo de ideia e sentimento (OMARTIAN, 1998, p. 30), e o ego masculino (...) é facilmente danificado (LEMAN, 2010, p. 116). Elas devem esvaziar-se de si mesmas e entregar-se à missão de, em oração (preferencialmente oração silenciosa), pedirem pela sua própria transformação e pela transformação de seus maridos. Nesse aspecto, é interessante notar que a desigualdade se explicita até mesmo na isenção do homem da responsabilidade de orar por sua esposa:

É natural entrar nesta maravilhosa aventura de oração imaginando se o seu marido vai orar um dia por você da mesma maneira que está orando por ele. Embora isso fosse certamente o máximo, não o tenha como garantido. Orar por seu marido será um ato de amor e sacrifício generoso e incondicional de sua parte. Você deve estar disposta a assumir esse compromisso sabendo que é muito possivel - e até bastante provável - que ele jamais venha a orar por você do mesmo modo (OMARTIAN, p. 16).

O homem é apresentado como alguém que precisa de um descanso, que não deve ser bombardeado com os problemas experimentados com os 
filhos e com a administração da casa no decorrer do dia. Também os problemas profissionais e ou pessoais da mulher não devem fazer parte da pauta de conversas do final do dia, afinal o super-homem precisa de um cochilo (JAKES, 1999 , p. 128). Essa invenção do homem como alheio à casa, indiferente à sua dinâmica e aos seus sujeitos, estipula o tipo de valoração que se confere ao espaço doméstico nas sociedades ocidentais contemporâneas. Também traduz as relações de poder estabelecidas na maneira como se institui a hierarquia doméstica: o homem (o chefe) não deve ser incomodado pela mulher (a secretária e ajudante de serviços gerais) com os problemas da casa e de seus moradores. Ele precisa ser poupado disso, e deve ser servido em todos os seus desejos. Dessa forma, a mulher é sobrecarregada com os afazeres domésticos e as demandas materiais e simbólicas de seus filhos e esposo, e o homem é desculpado por seu egoísmo latente. Essa sobrecarga é interpretada como constituinte do ser feminino. Há uma expectativa sociocultural de que a mulher seja sexualmente atraente, boa cozinheira, boa mãe, além de física, emocional e espiritualmente preparada (OMARTIAN, 1998, p. 33). A ajuda para dar conta de tudo isso viria de Deus:

Peģa ao Senhor para mostrar-lhe como tornar o seu lar um abrigo seguro, que proteja a sua família (...) Peça a Deus para ajudá-la a manter a casa limpa, a roupa lavada, a cozinha em ordem, a despensa e a geladeira cheias, e as camas arrumadas (p. 33).

\section{Considerações Finais}

A recepção de um discurso nunca acontece sem que haja ruídos. As mulheres são sujeitos ativos no processo de interpretação. Apesar de termos nos dedicado à análise do discurso de gênero presente na literatura evangélica, teríamos que ampliar a nossa reflexão no sentido de explicitar os ruídos no processo de transmissão e recepção desse discurso. Ao mesmo tempo em que consomem um tipo de literatura que tenta desenhar um perfil único de mulher evangélica, as mulheres negociam em seus discursos e práticas com os padrões religiosos do feminino, gerando novas possibilidades hermenêuticas. Evidentemente, essa interpretação está condicionada pelos códigos culturais dominantes, que tendem a definir as escolhas simbólicas dos sujeitos, ajustando-as ao seu mundo social, porém, na busca pela significação de seu cotidiano, as mulheres têm questionado as representações dominantes de gênero evocadas pela religião e por outros sistemas de sentido. Mas isso é matéria para outro capítulo. 


\section{Referências}

BERGER, Peter L. O Dossel Sagrado: elementos para uma teoria sociológica da religião. São Paulo: Paulinas, 1985.

BORDO, Susan. O corpo e a reprodução da feminidade: uma apropriação feminista de Foucault. In: JAGGAR, A. M. E BORDO, S. R. (Orgs.). Gênero, corpo, conhecimento. Rio de Janeiro: Rosa dos Tempos, 1997, p. 19-41.

BOURDIEU, Pierre. A dominação masculina. Rio de Janeiro: Bertrand Brasil, 1999.

BOUVAY, Claude. Religion et reproduction de l'asymétrie. Archives de Sciences Sociales des Religion. Paris, 1996, p. 143-161.

CHARTIER, Roger. La Lecture: une pratique culturel. Débat entre Pierre Bourdieu et Roger Chartier. In: CHARTIER, Roger (Org.). In: Pratiques de la lecture. Paris: Rivages, 1985, p. 267-294.

CHARTIER, Roger. O mundo como representação. Estudos Avançados, v. 11, n. 5. São Paulo, 1991, p. 173-191.

CUNHA, Rozane Rangel da. Megatendências para a Mulher Cristã. São Gonçalo: Adhonep, 1995.

DURKHEIM, Émile. As Formas Elementares de Vida Religiosa. São Paulo: Paulinas, 1989. FOUCAULT, Michel. Vigiar e Punir: história da violência nas prisões. Petrópolis: Vozes, 2007.

GEERTZ, Clifford. A Interpretação das Culturas. Rio de Janeiro: LTC, 1989.

GEERTZ, Clifford. O Saber Local. Novos Ensaios em Antropologia Interpretativa. Petrópolis: Vozes, 1998.

INSTITUTO PRÓ-LIVRO e AMORIN, Galeno (coord.). Retratos da Leitura no Brasil. São Paulo: Instituto Pró-Livro, 2008.

INSTITUTO PRÓ-LIVRO e FAILLA, Zoara (coord.). Retratos da Leitura no Brasil. São Paulo: Instituto Pró-Livro, 2012.

INSTITUTO PRÓ-LIVRO (coord.). Retratos da Leitura no Brasil. São Paulo: Instituto Pró-Livro, 2016.

JAKES, Thomas D. A dama, seu amado e seu Senhor. São Paulo: Mundo Cristão, 1999.

KEMP, Judith. A esposa que quero ser: o papel da esposa no casamento cristão. São Paulo: Mundo Cristão, 2006.

LAHAYE, Beverly. A Mulher controlada pelo Espírito. Belo Horizonte: Betânia, 1981.

LEMAN, Kevin. Transforme seu marido até sexta: mude o comportamento e a comunicação dele em 5 dias. São Paulo: Mundo Cristão, 2010.

OBSERVATÓRIO DO LIVRO E DA LEITURA e AMORIN, Galeno (coord.). Retratos da Leitura no Brasil. São Paulo: Instituto Pró-Livro, 2001.

OMARTIAN, Stormie. O poder da esposa que ora. São Paulo: Mundo Cristão, 1998. 
PERROT, Michelle. As mulheres ou os silêncios da história. Bauru: Edusc, 2005.

SAID, Edward. Orientalismo: o oriente como invenção do ocidente. São Paulo: Companhia das Letras, 1990.

SILVA, Eliane Moura da. Fundamentalismo evangélico e questões de gênero: em busca de perguntas. In: SOUZA, Sandra Duarte de. Gênero e Religião no Brasil: ensaios feministas. São Bernardo do Campo: Universidade Metodista de São Paulo, 2006, p. 11-27.

SÍNTESE DE INDICADORES SOCIAIS. Uma análise das condições de vida da população brasileira. Estudos e Pesquisas. Informação demográfica e socioeconômica, n. 36. Brasília: IBGE, 2016.

SOUZA, Beatriz Muniz e MARTINO, Luis Mauro Sá. A compreensão de um paradoxo. In: Sociologia da Religião e mudança social: católicos, protestantes e novos movimentos religiosos no Brasil. São Paulo: Paulus, 2004, p. 5-10.

SOUZA, Sandra Duarte de. Os desafios da abordagem de gênero para os estudos de religião no Brasil. In: AUGUSTO, Adailton Maciel (Org.). Ainda o sagrado selvagem. São Paulo: Fonte Editorial e Paulinas, 2010, p. 321-340.

WEBER, Max. A Ética Protestante e o Espírito do Capitalismo. São Paulo: Cia. Das Letras, 2004a.

WEBER, Max. Economia e Sociedade. Brasília: UNB, 2004b.

YOUSAFZAI, Malala e LAMB, Christina. Eu sou Malala. A história da garota que defendeu o direito à educação e foi baleada pelo Talibã. São Paulo: Cia. Das Letras, 2013.

Submetido em: 13-8-2017

Aceito em: 22-11-2017 